\title{
NEONATAL SEIZURE IN TOBRUCK MEDICAL CENTER
}

\author{
Nasren Gamal Saleh Al-Fraik ${ }^{1}$ and Khadeejah Miftah Ali Al-Khurum²* \\ ${ }^{1,2}$ Pediatric Department, Medical Collage Tobruck University, Tobruck, Libya \\ *hamad.kahlefa80@gmail.com
}

\begin{abstract}
Neonatal seizures are the most prominent feature of neurological dysfunction during neonatal period. Seizures in the neonatal population often present differently than in other age groups due to brain immaturity. However, in neonates there may be no clinical movement abnormalityeither because the seizures are subclinical or because they can not be noticed. This study aimed to determine the natural history, the time of onset, the etiological factors, the clinical types, the treatment, and the short-term outcomes of neonatal convulsion. This cross sectional descriptive study was conducted in The Neonatal Intensive Care Unit at Tobruck Medical Centre from the 1st of January 2017 to the end of January 2018.During this, 642 neonates were admitted to NICU, out of which 27 had seizures. $17(62.7 \%)$ of the babies were males and $10(37 \%)$ were females. All of them were Libyans; 70.3\% were from Tobruck city.

Keywords: Neonatal Seizure; Neonatal Intensive Care Unit; Risk factors; Complications; Outcome, Libya.

\section{Introduction}

A seizure or convulsion is a paroxysmal, time-restrained alternate in motor interest and/or conduct that are consequences of bizarre electric pastime in the neonatal brain. Seizures by definition occur in the first 4 weeks of life in a complete-time neonatal period and as much as forty four weeks from idea for premature infants. They are common in the course of the first 10 days of life. (Singh M, 2010).

Seizures during the neonatal period are a considerable problem, not only because they are symptoms of neurologic or metabolicdisorder, but also because there is a strong association between them and permanent handicaps in the survivors. The neonatal brain is susceptible to permanent damage as a consequence of the seizures (Wasterlain CG., 1979).

Seizures are more usual among neonates than in other age groups, and they influence about $1 \%$ of all neonates, with greater frequency in untimely or low birthweight new-borns compared to term babies. In the neonatal extensive care gadgets, the prevalence is going as excessive as 10-25\% out of which approximately $15 \%$ will die and $35-40 \%$ could have principal neurological squeal (Mikati MA et al., 2011).
\end{abstract}


Most of neonatal seizures remain complicated, mainly when clinicians depend best on clinical criteria. The medical manifestations of seizures in new-born vary from those visible features in older children and adults. The trouble is in electro-clinical dissociation, in which there's no temporal correspondence between electric paroxysms and repetitive stereotyped motor phenomena. There are few records that clinicians can base rational decisions about the appropriate remedies. Such remedies, unfortunately, are usually useless and can not adjust neurodevelopmental results.

Seizures in a new-born are one of the few neonatal neurological emergencies wherein set off prognosis, investigation and treatment are vital; as, behind schedule popularity of a treatable motive will have a sizeable effect on child's subsequent neurological results.

Seizures represent the mind's final common response to insult. The preliminary damage may be quick; however, membrane harm releases excitotoxic substances such as glutamate, which cause similarly epileptic interest. Magnetic resonance imaging of the brain has shown markedly decreased myelination in youngsters who had suffered from neonatal convulsions (Younkin DP, et al 1986).

\section{Materials and Methods}

This comparative study was conducted in Neonatal Department at Tobruck Medical Centre from $1^{\text {st }}$ of January 2017 up to the end of January 2018. The study population consisted of neonates admitted to The Neonatal Intensive Care Unit (NICU). During study period, all neonates developing clinically identifiable seizures before 28 days of life were enrolled in the study.

Personal information and a detailed history of all mothers including gender, nationality, residence, gestational age, age at onset, mode of delivery, and obstetrical and antenatal history of maternal diseases were recorded.

All new-borns' weight, and head circumference were recorded. The etiology of neonatal seizures were identified from imaging techniques such as ultrasound results as well as from the initial relevant investigations which included blood glucose levels, serum calcium, serum electrolytes, and cerebrospinal fluid examination for evidence of infection. Treatments received, as well as causes of deaths were also included within the records.

Seizure type was diagnosed by clinical observations made by the authors and the resident doctors. The etiology was based on laboratory findings, and /or imaging studies of the brain (ultrasonography, CT scan). The criteria for diagnosing various biochemical disorders were as follows: hypocalcaemia $\left(\mathrm{Ca}^{++}<7.0 \mathrm{mg} / \mathrm{dl}\right)$, hypomagnesaemia $\left(\mathrm{Mg}^{++}<1.5 \mathrm{mg} / \mathrm{dl}\right)$, hypernatremia $\left(\mathrm{Na}^{+}<135 \mathrm{mEq} / \mathrm{L}\right)$. Hypoglycemia was diagnosed if blood glucose levels were less than $45 \mathrm{mg} / \mathrm{dl}$ in term infants, and less than $40 \mathrm{mg} / \mathrm{dl}$ in preterm infants. CSF examination 
was considered abnormal when there were elevated CSF leukocytes, low CSF sugar, elevated CSF protein and/or positive culture (Volpe JJ. Neonatal Seizures, 2008), (ILAE, 2009).

Other non-seizures movements were differentiated from seizures and excluded; exclusion criteria included those with jitteriness or sleep-related muscular activities.

Limitations: There were limitations in some diagnostic investigations in the hospital like investigations for IEM (Inborn Error of Metabolism) as well as, MRI (Magnetic Resonance Imaging) and Arterial Blood Gases (ABG).

\section{Results}

Among the 642 neonates admitted to the neonatal care unit, during the study period, 27 (2.3\%) neonates (term and preterm) developed clinically identifiable seizures and were found eligible for the study.

Male gender dominated the admissions with (62.7\%) giving male to female ratio 1.7:1as showed in Table (1). According to maternal disease 3 babies out of the 27 delivered to mothers with chronic diseases: two with maternal hypertension and preeclampsia, and one with gestational diabetes mellitus.

Table (1): Demographic Data of New-Borns

\begin{tabular}{|c|c|c|c|}
\hline \multicolumn{2}{|c|}{} & Number & Percentage\% \\
\hline \multirow{2}{*}{ Onset of Seizure } & Early onset 1st 72 hrs & 25 & $92.5 \%$ \\
\cline { 2 - 4 } & Late onset >72 hrs & 2 & $7.4 \%$ \\
\hline \multirow{2}{*}{ Gestational Age } & Term & 24 & $88.8 \%$ \\
\cline { 2 - 4 } & Preterm & 3 & $11.1 \%$ \\
\hline \multirow{2}{*}{ Gender } & Male & 17 & $62.7 \%$ \\
\cline { 2 - 4 } & Female & 10 & $37 \%$ \\
\hline Nationality & Libyan & 27 & $100 \%$ \\
\hline \multirow{2}{*}{ Residence } & Tobruck & 19 & $70.3 \%$ \\
\cline { 2 - 4 } & Periphery & 8 & $29.6 \%$ \\
\hline \multirow{2}{*}{ Place and Transfer } & DR & 22 & $81.4 \%$ \\
\cline { 2 - 4 } & Private clinic & 5 & $\% 18.5$ \\
\hline
\end{tabular}

Table (2): Mode of Delivery and Resuscitation

\begin{tabular}{|c|c|c|}
\hline & Number & Percentage \% \\
\hline NVD & 12 & $44.4 \%$ \\
\hline CS & 51 & $55.5 \%$ \\
\hline Need Resuscitation & 17 & $62.9 \%$ \\
\hline
\end{tabular}


Out of the 27 babies, 23 (85\%) had normal birth weight of the rest three babies $(11.1 \%)$ were LBW $(<2.5 \mathrm{~kg})$ and one baby $(3.7 \%)$ was large for gestational age $(>4.5 \mathrm{~kg})$.

Regarding head circumference the vast majority of the babies $22(81.4 \%)$ lay within normal range whereas 4 babies $(14.8 \%$ ) were less than $33 \mathrm{~cm}$, among these 4 babies 3 were preterm ones. On the other hand, 1 baby $(3.7 \%)$ was above $37 \mathrm{~cm}$.

Table (3): Time of Onset of Seizure in Studied New-Born

\begin{tabular}{|c|c|c|}
\hline Day of Onset & Number & Percentage \% \\
\hline First Day & 17 & $62.9 \%$ \\
\hline Second Day & 5 & $18.5 \%$ \\
\hline Third Day & 3 & $11.1 \%$ \\
\hline More & 2 & $7.4 \%$ \\
\hline
\end{tabular}

Table (4): Type of Seizure

\begin{tabular}{|c|c|c|}
\hline & Number & Percentage \% \\
\hline Tonic-Clonic & 20 & $74 \%$ \\
\hline Subtle & 7 & $25.9 \%$ \\
\hline Total & 27 & $100 \%$ \\
\hline
\end{tabular}

Table (5) Data of Laboratory and Imaging

\begin{tabular}{|c|c|c|c|}
\hline \multicolumn{2}{|c|}{} & Number & Percentage \% \\
\hline \multirow{2}{*}{ CSF } & Done & 18 & $66.6 \%$ \\
\cline { 2 - 4 } & Not Done & 9 & $33.3 \%$ \\
\hline \multirow{2}{*}{ USG } & Done & 22 & $81.4 \%$ \\
\cline { 2 - 4 } & Not Done & 5 & $18.5 \%$ \\
\hline \multirow{2}{*}{$\mathrm{Ca}$} & Low & 9 & $33.3 \%$ \\
\cline { 2 - 4 } & Normal & 18 & $66.6 \%$ \\
\hline \multirow{2}{*}{ Bl. Sugar } & Hypoglycemia & 2 & $7.4 \%$ \\
\cline { 2 - 4 } & Normal & 25 & $92.5 \%$ \\
\hline \multirow{2}{*}{$\mathrm{Na}$} & Low & 5 & $18.5 \%$ \\
\cline { 2 - 4 } & Normal & 22 & $81.4 \%$ \\
\hline
\end{tabular}

Table (6): Distribution of Babies According to Imaging

\begin{tabular}{|c|c|}
\hline Type of imaging & No. \\
\hline Brain USG & $22 / 27$ \\
\hline CT Scan & $2 / 22$ \\
\hline EEG & $1 / 22$ \\
\hline MRI & 0 \\
\hline
\end{tabular}


Table (7): Distribution of Babies According to Place of Transfer $(n=27)$

\begin{tabular}{|c|c|c|c|c|}
\hline Place of Transfer & \multicolumn{2}{|c|}{ Tobruck } & \multicolumn{2}{c|}{ Outside Tobruck } \\
\hline & NO. & $\%$ & NO. & $\%$ \\
\hline Direct from Home & 16 & $84.2 \%$ & 6 & $75 \%$ \\
\hline Private Clinic & 3 & $15.7 \%$ & 2 & $25 \%$ \\
\hline Total & 19 & $100 \%$ & 8 & $100 \%$ \\
\hline
\end{tabular}

Regarding causes of fits, birth asphyxia was considered as a leadingcause of convulsions 23 babies $(85.1 \%)$; 9 of them had an isolatedasphyxia. The other 14 babies had additional problems: 9 babies had hypocalcaemia, 5 babieshad electrolyte disturbances, and 2 babieshad hypoglycaemia. In addition, it was noticed that there were some infections namely sepsis within 2babies (7.4\%) and meningitis within 1 baby (3.7\%).

The commonest biochemical abnormality demonstrated in our study was hypocalcaemia 9 babies (33.3\%), then electrolyte disturbance5 babies (18.5\%), hypomagnesaemia 2 (7.4) babies, and hypoglycemia 2babies (7.4\%) where one of them was an IDM.

Inborn error of metabolism was in the form of maple syrup urine disease in 1 baby (3.7\%). Intracranial hemorrhage (IVH) was established in 3babies (11.1\%); two of them were preterm.3 babies(11.1\%) were diagnosed of CNS structural defects: one hydrocephalus, one meningeocele and one holoprosencephaly.

All babies received one or more types of treatment during their admission. 26babies (96.2\%) received intravenous Phenytoin as first line of treatment where as19 babies $(70.3 \%)$ received oral phenobarbitone. Dextrose $10 \%$ was empirically given to most of the babies, and calcium gluconate was given to 9 babies $(33.3 \%) ; 3$ resistant cases for treatment received Pyridoxine (11\%). 6 babies (22.2\%) discharged on one anticonvulsant drug.

Table (8): Out Come

\begin{tabular}{|c|c|c|}
\hline & Number & Percentage \% \\
\hline Discharged without Treatment & 8 & $29.6 \%$ \\
\hline Discharged with Treatment & 6 & $22.2 \%$ \\
\hline Died & 11 & $40.7 \%$ \\
\hline Transferred & 2 & $7.4 \%$ \\
\hline
\end{tabular}


Table (9): Correlation Between Babies' Sex and the Outcome

\begin{tabular}{|c|c|c|c|c|}
\hline \multirow{2}{*}{ Outcome } & \multicolumn{2}{|c|}{ Sex } & \multirow{2}{*}{ Total } & \multirow{2}{*}{ P-value } \\
\cline { 2 - 3 } & Male & Female & & \\
\cline { 2 - 3 } & No.\% & No. \% & & \multirow{2}{*}{0.113} \\
\hline Discharged without Treatment & 5 & 3 & 8 & \\
\hline Discharged with Treatment & 4 & 2 & 6 & \\
\hline Died & 0 & 11 & 11 & \\
\hline Transferred & 1 & 1 & 2 & \\
\hline
\end{tabular}

Chi-Square Tests: $\mathrm{x}^{2}=1.551, \mathrm{df}=20, \mathrm{p}=0.113$.

Table (10): Correlation Between Gestational Age and the Outcome

\begin{tabular}{|c|c|c|c|c|}
\hline \multirow{2}{*}{ Outcome } & \multicolumn{2}{|c|}{ GA } & \multirow{2}{*}{ Total } & \multirow{2}{*}{ P-value } \\
\cline { 2 - 3 } & Term & Preterm & & \\
\cline { 2 - 3 } & No.\% & No.\% & & \\
\hline Discharged & 2 & 12 & 14 & \multirow{2}{*}{0.534} \\
\hline Died & 1 & 10 & 11 & \\
\hline Transferred & 0 & 2 & 2 & \\
\hline
\end{tabular}

Chi-Square Tests: $\mathrm{x}^{2}=3.651, \mathrm{df}=4, \mathrm{p}=0.534$.

Table (11): Correlation Between Mode of Delivery and the Outcome

\begin{tabular}{|c|c|c|c|c|}
\hline \multirow{2}{*}{ Outcome } & \multicolumn{2}{|c|}{ Mode of Delivery } & \multirow{2}{*}{} & \multirow{2}{*}{ P-value } \\
\cline { 2 - 4 } & NVD & C/S & \multirow{2}{*}{ Total } & \\
\cline { 2 - 3 } & No.\% & No. \% & & \\
\hline Discharged & 7 & 7 & 14 & \multirow{2}{*}{0.695} \\
\hline Died & 6 & 5 & 11 & \\
\hline Transferred & 2 & 0 & 2 & \\
\hline
\end{tabular}

Chi-Square Tests: $\mathrm{x}^{2}=2.641, \mathrm{df}=4, \mathrm{p}=0.695$.

\section{Correlation Between Main Causes and the Outcome}

Prognosis was poor in babies with IEM 1/1 died followed by CNS structural defects $3 / 3$ died and ICH 2/3 died. Babies with birth asphyxia 5/23 (21.7\%) of them died. There is a significance association between main causes of neonatal convulsions and the outcome with $\mathrm{p}=0.025$. (Chi-SquareTests: $\mathrm{x} 2=31.652$, $\mathrm{df}=20, \mathrm{p}=.025$.) $\mathrm{e}$. 
Table (12): Correlation Between Time of Onset and the Outcome

\begin{tabular}{|c|c|c|c|c|c|c|c|}
\hline \multirow[t]{3}{*}{ Outcome } & \multicolumn{5}{|c|}{ Time of Onset } & \multirow{3}{*}{ Total } & \multirow{3}{*}{ P-value } \\
\hline & & & $>24-48 \mathrm{Hrs}$ & $>48-72 \mathrm{Hrs}$ & $>72 \mathrm{Hrs}$ & & \\
\hline & \multicolumn{2}{|c|}{ No\% } & No\% & No\% & No\% & & \\
\hline Discharged & 9 & 7 & 1 & 2 & 2 & 14 & \multirow{3}{*}{0.455} \\
\hline Died & 6 & 5 & 4 & 1 & 0 & 11 & \\
\hline Transferred & 2 & 0 & 0 & 0 & 0 & 2 & \\
\hline Total & 17 & & 5 & 3 & 2 & & \\
\hline
\end{tabular}

Chi-Square Tests: $\mathrm{x} 2=3.651, \mathrm{df}=4, \mathrm{p}=0.455$.

\section{Discussion}

It is well known that seizures are of greater commonplace within the neonatal length than anyother stage of existence. Its prevalence, as reported by various research, varied from 0.1 $0.5 \%$ in time period neonates and from $10-22 \%$ in preterm neonates(Rennie JM, Bylan GB.2002).Al.yasiri.A.Adeebah.(2015) reported a higher incidence figure with $3.9 \%$ which is almost similar tothe one mentioned by Mosley M.(2010)which is 3.4\%.Our examination shows that out of 642 neonates admitted during the examination duration 27 have been found with exclusive clinical troubles, (time period and preterm) neonates advanced seizures; this number gives an incidence of $2.3 \%$. There is also a consistence male predominance of all kinds of seizures. This occurrence of seizures in adult males is described in many previous studies such as Mary Jo Lanska, Douglas J. Lanska, et al (2000), Anand et al (Anand V, Nair PM.(2014)), Alcover-Bloch E, Campistol J, et al (2004), and Sabzehei M., et.al.2014.They mentioned that neonatal seizures are better known in males.In the current study, male subjects are dominant; they constitute $62.7 \%$. Concerning the subjects from Tobruck, the ratio of males to females' is $1.7: 1.19$ respectively. $81.4 \%$ of the whole babies were admitted immediately from transport where as the other $18.5 \%$ of the infants were transferred from other hospitals.

Most of the neonates24 (88.8\%) who developed seizures, in our take a look at, were complete term ones. Males and full term dominance results are similar to previous ones reported by Yaser S. Abd. (2004) and Al.Marzoki.M.Jasim(2010). They concluded that full term babies were affected more than those who were preterm: $93.1 \%, 95.4 \%$ respectively and the majority of them have been males. Prevalence of fits during the first week of life and during the first seventy two hours were reported by other researchers such as Najeeb S, Qureshi AM, et al (2012) and Malik BA, Butt MA, et al (2005).

Most of neonatal seizures passed off in 1st day or at time of delivery even as in second and third days were $29.6 \%$ infants, and > 3 - 7 days were $7.4 \%$ neonates. This was explained by using birth asphyxia as a main motive of fits, which appeared to be the strongest predictors of early onset seizure. 
However, in a study by Kumar Ashok, (2004) it was found that within most neonatal seizures of late onset, metabolic abnormalitieswasthe most common dominant factor contributing to neonatal seizures. Najeeb S, Qureshi AM, et al (2012) mentioned that mode of transport in $67 \%$ of babies with seizures was vaginal shipping and in $17 \%$ by cesarean segment and assisted in $17 \%$.In our examination, vaginal deliveries were conducted in $12(44.4 \%)$ where as cesarean sections were executed to 15 (55.5\%) mothers.Al.yasiri.A.Adeebah (2015) reported comparable determine to us: in $66 \%$ normal deliveries and $34 \% \mathrm{c} / \mathrm{s}$.

Out of the 27 neonates in our study, $23(85 \%)$ had everyday beginning weight, 3 infants $(11.1 \%)$ were $\mathrm{lbw}$, and only 1 baby $(3.7 \%)$ was large for gestational age (> 4.five $\mathrm{kg})$. The head circumference of 22 neonates (81.four\%) lay in normal range and of 4 babies $(14.8 \%)$ was less than $33 \mathrm{~cm}$. The above effects are similar to Al.yasiri.A.Adeebah (2015) where $87 \%$ of babies birth weight was above $2500 \mathrm{gm}$ with mean of $3148+717$ and $12 \%$ was under $2500 \mathrm{gm}$. However, this was barely first rate than that found by Najeeb S, Qureshi AM, et al (2012). They announced lower birth weight; out of 100 neonates with seizures, $35 \%$ of them had lbw with mean $2.56+0.57 \mathrm{~kg}$.

Sambhaji S etal. (2013) found that the most common type of seizure was subtle 40.1\%, followed by clonic 24.2\%. Najeeb S, Qureshi AM, et al (2012) described tonic clonic seizure $28 \%$ as widespread accompanied through multi focal clonic, and focal tonic seizures (25\% every), diffused $21 \%$, focal clonic $20 \%$, myoclonic and focal tonic three $\%$ each. Our results show that 20 infants (74\%) had tonic-clonic convulsion and diffused in 7 babies (25.9\%) and tonic 11 infants $(7 \%)$.

In a study by Lopes A, VilanA,et.al (2003) anomalies within the cranial ultrasound were correlated with clinical evolution, and still the primary line exam in the initial method to underlying pathology.We have executed cranial ultrasound in 22 infants (81.4\%) in step with clinical assessment and development of the disease; different neuroimaging (ct) have been performed to 2/22; they have reviled three neonates with ich.This goes with Lopes A, VilanA,et.al (2003) study where cranial ultrasound performed in 86.8\%.However in AlcoverBloch E, CampistolJ,et al (2003) head ultrasound was odd in forty four/seventy seven of newborns; ct test and/or mri were unusual in 31/77 new child.

Beginning asphyxia is the most common reason for neonatal seizures found globally (Doménech-Martínez E,et.al, 2001). It is considered the predominant etiology in both premature and full term neonates, occurring in the first 72 hours of life (Gabriel M. Ronen, Sharon Penney,et al 2008). Our findings are in settlement with that, with predominance in full time period babies. They also show that delivery asphyxia was the main reason of convulsions in 23 infants $(85 \%)$, nine of them were an isolated asphyxia and the remaining 14 neonates had extra issues which coexisted with birth asphyxia such as hypocalcaemia (33.three\%), electrolyte disturbances, hypoglycaemia,hypomagnesaemia, hyponatremia (15.8\%), 
contamination, ich and cns structural defects (11\%). These findings are similar to a study by Najeeb S, Qureshi AM, et al (2012) where 46\% of the neonates were with birth asphyxia.

Hypoglycemia, hypocalcaemia, and hypo/hypernatremia are crucial biochemical abnormalities causing neonatalseizures with hypocalcaemia as the main biochemical abnormalities (Rennie JM, Bylan GB., 2002). This goes with our commentary in which an expansion of biochemical abnormalities was verified in our infants as a number one cause of seizures. It included hypocalcaemia in $9(33.3 \%)$, electrolyte disturbances 5 neonates $(15.8 \%)$, hypoglycemia in 2 (7.4\%) and 2 babies (7.4\%) with hypomagnesaemia.

Another crucial etiological elements of neonatal seizure encompassed intracranial haemorrhage; its occurrence ranged from 6\% (MahmoodArshad, Syed QamarZaman, et.al. 2014) to $6.9 \%$ (Sabzehei M., Basiri B., et.al.2014). However, in Bushra AM, Butt MA, et al (2005), and Alcover et al., (2003) found with a higher rate $9.5 \%$ and $13 \%$ respectively where the majority of these babies were less than 36 weeks. In contrast to previous studies, we had only 3babies (11\%) with ICH.

Treatment for neonatal seizures includes specific remedy for the underlying cause and the use of antiepileptic capsules. Antiepileptic drugs are used to forestall all electrographic seizure pastimes.Theremedy needs to be tailored to the particular situation (Wong Michael.(2006). In Alcover-Bloch E, Campistol J. et al (2003), phenobarbital was the preliminary remedy in $81.8 \%$, and $55.7 \%$ needed the remedy at discharge. In the current study, we used phenytoin as the first line of remedy in (96\%) accompanied via oral phenobarbitone (70\%). Because IVis not available in our clinic, pyridoxine is used for $11 \%$ of the patients. $22.2 \%$ of the babies discharged on anticonvulsant therapy whilst $29.6 \%$ of them recovered and discharged home without extra therapy. Unfortunately, $40.7 \%$ of the neonates died.This is comparable to the findings reported by Sahana et al ,G. Sahana, B. Anjaiah (2014) and Al.yasiri.A.Adeebah (2015) in which respectively, 49.54\%, 56.6\% neonates recovered without any remedies where as $32.11 \%, 26.2 \%$ of the neonates recovered with remedies, and ,unfortunately, $18.35 \%$, $17.2 \%$ of the neonates died.

There was no obvious connection between the results and gender, early or past due onset of neonatal convulsion, gestational age, or vaginally or with the aid of c/s delivery. Statistical evaluation confirmed an important affiliation among foremost reasons of neonatal convulsions and the final results with $\mathrm{p}=$ zero.half.

\section{Conclusions}

- Most of the neonates who had seizures were males and were full time period.

- the most commonetiology of seizure was beginning asphyxia.

- hypocalcaemia was the maximum commonplace biochemical abnormality observed by using hyponatremia.

- tonic clonic seizure represented the commonest sort of seizure. 
- phenytoin through oral phenobarbitone was the most prescribed anticonvulsan.

- inborn errors of metabolism, cans structural defects and ICH constituted the highest mortality rate.

- there is a good sized affiliation between foremost reasons of neonatal convulsions and the final results with $p=0$.half

\section{Recommendations}

We propose the development of antenatal offerings and obstetrical care with ordinary monitoring of fetal coronary heart rate to ensure secure transport and suitable neonatal resuscitation to avoid birth asphyxia. We also propose the development of the laboratory offerings and supplying it with extra advanced techniques for discovering and diagnosing inborn errors of metabolism. More research needs to be conducted about a large sample that includes a large scale of other hospitals.

\section{References}

- Al.Marzoki. M.Jasim. (2010). Clinco-Biochemical Profile of Neonatal Seizures at Dept. Pediatrics, Babylon Medical College, Babylon University, Hilla-Iraq- Babylon Maternity and Children Teaching Hospital, Des; QMJ VOL.6 No.10:163-168.

- Al.yasiri.A.Adeebah. (2015). the etiology of seizures among neonates admitted to Babylon Gynecology and Pediatrics teaching hospital; Dept. Pediatrics, Babylon Medical College, Babylon University, Hilla-Iraq- Babylon Maternity and Children Teaching Hospital, 2 (1), 3040.

- Alcover-Bloch E, Campistol J, et al (2004). Neonatal seizures, our experience. Rev Neurol.; 38:808-812.

- Alcover-Bloch E, CampistolJ, et al (2003). Neonatal seizures, our experience; Hospital Sant Joan de Déu, Esplugues de Ll, Barcelona, Spain. Rev Neurol. May 1-15;(9):80-81.

- Anand V, Nair PM.(2014). Neonatal seizures: Predictors of adverse outcome; Department of Pediatrics, SreeGokulam Medical College and Research Foundation, Thiruvananthapuram, Kerala, India. J PediatrNeurosci.May;9(2):97-9. Doi: 10.4103/1817-1745.139261.

- Bushra AM, Butt MA, et al (2005). "Seizures etiology in the newborn period", J Coll Physicians Surg Pak, 15(12)786-90.

- Doménech-Martínez E, Castro-CondeJR, et al (2001). Neonatal convulsions: influence of the electroencephalographic pattern and the response to treatment on the outcome; Servicio de Neonatología, Hospital Universitario de Canarias, La Laguna, spain.Revista de Neurologia , 37(5):413-420. 
- G. Sahana, B. Anjaiah (2014). Clinical profile of neonatal seizures, Int J Med Applied Sci.; $3: 21-7$.

- Gabriel M. Ronen, Sharon Penney, et al (2008). The epidemiology of clinical neonatal seizures in Newfoundland : A population-based study; Department of Pediatrics, McMaster University, Hamilton, Ontario, Canada.JPediatr.Jan;134(1):71-5.

- ILAE (2009). Proposal for revised classification of epilepsies and epileptic syndromes. Commission on Classification and Terminology of the International League Against Epilepsy. Epilepsia; 30(4):3 89-399.

- Kumar Ashok, Veenu Gupta, et al (2004). Biochemical abnormalities in neonatal seizures; The department of pediatrics, Institute of Medical Sciences, and the Department of Metallurgy, Institute of Technology, Banaras Hindu University, Varanasi. India.volume 32.

- Lopes A, Vilan A, et al (2003). Neonatal seizures in a tertiary neonatal intensive care unit. Acta Med Port. Nov-Dec;25(6):368-74.

- MahmoodArshad, Syed QamarZaman, et al (2014). Neonatal seizures; types, etiology at a tertiary care hospital; PNS Shifa Naval Hospital, Karachi. Pakistan. Professional Med J; 21(5):1048-1053.

- Malik BA, Butt MA, et al (2005). Seizures etiology in the newborn period. J Coll Physicians Surg Pak.; 15:786-790.

- Mary Jo Lanska, Douglas J. Lanska, et al (2000). A population-based study of neonatal seizures in Fayette County, Kentucky.NeurologyAprilvol. 45 no. 4 724-732.

- Mikati MA, Kliegman RM, et al (2011). Seizures in childhood. Philadelphia: WB Saunders 586: 2013-2037.

- Mosley M. (2010). "Neonatal seizure Pediatric in review”; 31: 127-8.

- Najeeb S, Qureshi AM, et al (2012). Aetiology and types of neonatal seizures presenting at Ayub Teaching Hospital Abbottabad. J Ayub Med Coll Abbottabad.;24(1):33-37.

- Rennie JM, Bylan GB. (2002). Neonatal seizures. In: David TJ, ed. Recent Advances in Paediatrics 18. Edinburgh: Churchill Livingstone; p. 19-32.

- Sabzehei M., Basiri B., et al (2014). "The Etiology, Clinical Type, and Short Outcome of Seizures in Newborns Hospitalized in Besat Hospital/Hamadan/ Iran", Iran J Child Neural, spring; 8(2): 24-28. 
- Sambhaji S Wagh, Krupa J Rambhia A (2013). study of clinical profile of neonatal seizures. International Journal of Recent Trends in Science and Technology. October; 20(3) 343-348.

- Singh M. (2010). Neurological disorders. In: textbook of care of newborn. Delhi Sagarpublication; 340-344.

- Volpe JJ. Neonatal Seizures. (2008). In Neurology of the newborn. Philadelphia: WB Saunders.Neonatal seizures; pp 172-225.

- Wasterlain CG. Does anoxemia play a role in the effects of neonatal seizures on brain growth? An experimental study in the rat. Eur Neurol 1979; 18:222-9.

- Wong Michael (2006). Neonatal Seizures; University School of Medicine and an epileptologist in the Pediatric Epilepsy Center at St. Louis Children's Hospital.Washington. USA.

- Yaser S. Abd. (2004). "a clinical study of neonatal convulsion in al Khansaah teaching hospital for pediatrics in Mosul”, thesis for fellowship degree of FIBMS pediatric; 23.

- Younkin DP, Delivoria-Papdopoulos M, et al (1986). Cerebral metabolic effects of neonatal seizures measured with in vivo pNMR spectroscopy. Ann Neurol: 20,513-519. 